\title{
The Relationship between Size and Performance of Palestinian Water Service Providers
}

\author{
Abdullah Murrar 1,2,3 \\ ${ }^{1}$ Business Administration, Al-Quds University of Jerusalem, Jerusalem, Palestine \\ ${ }^{2}$ Faculty of Graduate Studies, Strategic Planning \& Fundraising, Arab American University Jenin, Jenin, Palestine \\ ${ }^{3}$ Water Sector Regulatory Council, Ramallah, Palestine \\ Email: abdullah.murrar@gmail.com
}

How to cite this paper: Murrar, A. (2017) The Relationship between Size and Performance of Palestinian Water Service Providers. Journal of Water Resource and Protection, 9, 536-552.

https://doi.org/10.4236/jwarp.2017.95035

Received: March 30, 2017

Accepted: April 27, 2017

Published: April 30, 2017

Copyright $\odot 2017$ by author and Scientific Research Publishing Inc. This work is licensed under the Creative Commons Attribution International License (CC BY 4.0).

http://creativecommons.org/licenses/by/4.0/

(c) (i) Open Access

\begin{abstract}
Studies investigating the relationship between size and performance of water service providers are abundant. Yet, this relationship has not been fully addressed in Palestinian water sector, particularly, after the issuance of water law 2014 which calls for merging water providers into large regional utilities. This research evaluates the significant effect of the size of Palestinian water service providers on non-revenue water, staff productivity, collection efficiency, average consumption, average price, operating and maintenance cost, working ratio, and gross profit. The multivariate analysis shows that there are significant differences in working ratio, non-revenue water, staff productivity, average price, and gross profit based on the size. On the other side, no significant differences have been found in average daily consumption, operating and maintenance cost per unit, and collection efficiency based on those providers' size. The small service providers perform better in non-revenue water, staff productivity, and collection efficiency; wherein, large service providers are more profitable than small service providers. Implications of these findings by conducting further studies will add the value for better merging of the Palestinian water providers and the reforming process.
\end{abstract}

\section{Keywords}

Palestinian Water Law 2014, Palestinian Water Service Providers, Performance, PWA, WSRC

\section{Introduction}

In water sector, finding a way to measure the performance of water service providers has been one of main concerns of regulatory bodies, non-profit organiza- 
tions and government entities around the world. Like electricity and energy sectors, this sector has received very special attention, not only because water is vital for every human being, but also because of its operation, management, and structure as a natural monopoly. In essence, the relevant studies about performance have assessed service providers' efficiency in a way of input and output in term of cost and production. It's necessary therefore, to look to other areas wherein service providers can work within to achieve financial sustainability.

Besides the efficiency of water providers within the sector, some other detailed topics such as non-revenue water, profitability, bills collection efficiency, and staff productivity, have received considerable interest throughout literatures. Regarding this, non-revenue water can influence in three ways: first, it decreases operating revenue due to unissued invoices. The second way consists of increasing cost of production, operation, and maintenance due to raise in cost of purchases and operations per unit produced and sold. The third one; it raises budget allocation for capital expenditure due to high investment level. Specifically, whether or not high level of non-revenue water, it's a core indicator to measure efficiency and sustainability of water providers. The less the non-revenue water, the more the efficiency and sustainability.

Together, employees' productivity and collection efficiency of service provider are major concerns of recent studies. The bills collection efficiency is necessary for continuity of water service providers. If no receipt by those providers, then, it will be difficult to continue delivering water services to their customers. The more regular invoice payment, the more the cash inflow and financial sustainability. However, the employees' productivity is a necessary indicator for efficiency of service providers. The less the number of employees and the large output produced, the more the productivity and financial sustainability.

Within the context of sustainability and performance areas, the relationship between water service providers' size and performance has many facets. Many studies show small water providers outperform large-scale ones in collection efficiency and non-revenue water reduction. However, in different countries, it proposes that large providers achieve more efficiency in non-revenue water reduction and water bills collections. The same results would be applicable for other performance sides such as staff productivity, working ratio, and profitability. As a result, carrying out a case study is necessary before taking decisions especially in recent years; where, a merging trend of small water service providers into large water utilities is becoming widely implemented in many countries.

The aim of this paper hence is to analyze, using multivariate technique, the relationship between size of Palestinian water service providers and performance areas. Those areas are important for service providers' financial sustainability and continuity in delivering water services. This is to be done by measuring performance of water providers at different sizes. Before that, next section in this paper shortly reviews studies related to this performance and size. Then it presents model specification and methodology that are applied. The analysis and policy implications have been carefully developed to provide practical implications for better performance of water sector. 


\section{Related Literature}

Many literatures have tackled the relationship between performance and size of water service providers. Some studies indicate large size of water utilities may perform better than small due to economies of scale, scope and density. Others may argue that small provider is more efficient, manageable, and smart. It is imperative, therefore, to review related studies which to that end lead to exert the effect of small, medium and large size on different areas of performance and achievement.

Peda, Grosi, and Liik [1] studied the influence of ownership and size for 43 water utilities serve $68 \%$ of Estonian population on efficiency. The researchers found, the larger the size of water providers, the more the efficiency achieved. In water supply, many indicators measure the performance of service providers. High volume percent of non-revenue water explains inefficient and poor management of water providers. Financially, non-revenue water leads to increase the cost of cubic meter sold, and decrease the revenue expected to be billed. A study in Zimbabwe shows service providers especially large size and in developed countries have better performance because of benchmarking and emerging of new equipment for leak detection. However, those capabilities are limited in developing countries and small utilities [2]. In South Africa, there is a study on $75 \%$ of total volume of water supply showed non-revenue water estimated for the whole country was $36.8 \%$. The non-revenue water formed $46 \%$ of total cost for rural or small providers; where it about $35 \%$ of urban service providers cost [3]. As in summary, those related studies indicated that the larger the size of water providers, the more the efficiency achieved especially in non-revenue water reduction.

In the opposite direction, in some countries, small size of service providers may be more efficient than large. Cross sectional data has been collected from International Benchmarking Network for Water and Sanitation Utilities Database "IBNET" for water utilities serve in 68 countries [4]. The study finds small size of service providers performs more in non-revenue reduction and therefore, less in non-revenue water percent. The author concludes economies of scales are more evident in small service providers and tend to decrease in relation to the size of the operation. Bonifaz and Itakura, [5] analyzed the inefficiency and whether or not economies of scale exist in large urban water utilities in Latin America. The study sketches positive relationship between inefficiency and public owned and managed water service providers. From cost saving issue, the finding indicates no potential decreasing cost with large size of water providers. Therefore, the larger the size of water service provider, the more the inefficiency level, other things being constant.

In this paper, the researcher concludes that service providers' size has effect on non-revenue water and efficiency. In some countries, small water providers perform more efficient in non-revenue water reduction than large providers. Where in other countries, large providers can decrease unit cost, emerging new equipment for leak detection and achieve more efficiency. In addition to water 
providers' size, other determinants may affect performance and they vary in different conditions and service areas.

Collection efficiency of water invoices is another area that service providers may be evaluated. William Connell [6] studied the impact of late payment on cash flow. The study finds smaller and medium enterprise sizes are particularly exposed to late payments compared with large enterprises. Abdullah Murrar [7] concludes that large scale of service providers have significant capabilities compared with small providers. Those capabilities, such as large number of collection centers and implementing advance technology can motivate customers to pay their water bills. However, small water providers can also motivate customers to pay their invoices. A cross-sectional data for eight small urban centers in Uganda has been obtained to determine customer decisions to pay water bills promptly. The study shows that social pressure strongly motivates customers to pay water bills [8]. Whether the motivation of customers is performed through social pressure or through new capabilities; the more the bills payment from customers, the more the water providers' financial sustainability achieved. It is important therefore to know which size has significant effect on collection efficiency compared with other sizes.

The size may affect positively on produced unit cost. Generally, the larger the scale of service providers, the lesser the cost of unit produced. A study for World Bank calculates how much operation and maintenance costs would increase with a doubling of service providers' size. Three different results have been found, the economies of scale were found in 10 cases, constant returns of scale in 7, and diseconomies of scale in 3 cases. The study shows, a water provider that doubles the size of served population would increase its costs by 61 percent and 75 percent in Africa and Vietnam respectively. However, some water providers have less benefit from double size as in Peru and Indonesia [9].

The size of service provider hence may affect staff productivity; Leung, Meh and Terajima [10] studied this effect and relation in manufacturing and nonmanufacturing firms for both in USA and Canada. The researchers found direct relationship between size of the firm and total factor productivity in both manufacturing and non-manufacturing firms. The average number of employees in large firms relative to output is less than in small ones, especially in manufacturing firms. In Palestinian water sector, three forms of water providers in term of production and size. Some of them produce and distribute water to their customers. Other providers only distribute it without production, and the other type produces partially, purchases the rest and then distributes it to end customers. It is important therefore, to know which size and structure from those types can achieve more in staff productivity.

Given the fact that generating profits is a key aspect of maintaining water service providers' financial viability and sustainability, the size of service providers may have positive or negative effect on the profit. For profit maximization purposes, a study over 1132 water service providers in Albania, Brazil, Norway, Russia and Poland has been developed. The findings show significant financial 
achievements by larger utilities at different aspects. The author recommends decision makers to gain from those achievements to merge small water providers into large scale [11]. Another study from France measured the benefit in water sold to final customers and water network losses. The study shows significant economies of scale, positive degree of economies of scope, short-run returns to production density and returns to customer density. Those results indicate that small local communities may benefit from merging into large water districts [12]. However, others may argue that small water providers may generate more profit percentage comparing with large ones. González and García [13] conclude that when there is greater scope of actions, it may be diseconomies conditions which can cancel out possible benefits related to the size of operations. Therefore, the researchers recommend carrying out case studies prior taking a decision.

\section{Research Methodology}

A review of related studies clearly indicates many performance areas are affected by size of service providers. This research will test by conducting multivariate analysis the relationship and significant impact of service providers' size on non-revenue water, staff productivity, collection efficiency, average consumption, average price, operating and maintenance cost, working ratio, and gross profit.

The performance areas are selected to achieve financial sustainability of service providers. Four dimensions have been considered: firstly, profit generated by service providers. For this factor, operating, maintenance cost, and average price are added. On the other hand, gross profit margin and working ratio have been included to support this dimension. Generally, less cost and high price, produce more in gross and net profit margin. Secondly, consumption issue, the average consumption may indicate as ability of Palestinian service provider whether small, medium or large to deliver quality of service and continuous supply. Generally, in Palestine, there is shortage problem in water supply. In some areas such as in Yatta \& Dura, the per capita per person is less than 30 liters per day due to unavailability of water [7]. A study shows that domestic water consumption depends on adequacy of water supply up to customer satisfaction [14]. Thirdly, it is the bills collection efficiency dimension. It has been known that generating profit through increasing price and decreasing cost is the first step in financial viability. However, this profit shall be collected and changed into cash inflow to enable service provider to pay due invoices and operating expenses. For this reason, collection efficiency has been reflected as key performance area. The last dimension in this performance is service providers' efficiency in nonrevenue water reduction and employees' productivity. In summary, the less the number of employees and the large output produced, the more the productivity achieved. On the other hand, the less the non-revenue water percentage, the more the efficiency and financial sustainability.

To enrich understanding in these performance dimensions, site visit to different sizes of Palestinian water service providers to perform interviews with key managers was the first process in this method. The purpose of this visit was to 
recognize the environment wherein different sizes of service providers work in, and to verify the exerted factors with those managers. According to the Water Sector Regulator Council, (WSRC) service providers are classified into broad three categories based on number of connections they serve. The first one is Small, where, they serve more than 2000 connections. Medium category providers serve from 2000 to 8000 connections. However, the third category is related to large scale of distribution due to their service more than 8000 active connections [15].

In addition to interviews, secondary data has been collected from published performance indicator reports of Palestinian water services providers. The Performance Reports used to be published by the Palestinian Water Authority (PWA); and currently are being published by Water Sector Regulator Council (WSRC); with full support in terms of financial and technical advisors appointed by Deutsche Gesellschaftfuer Internationale Zusammenarbeit (GIZ) Water Program. According to Water Sector Regulatory Council, published data in report 2015 covers service provides that serve more than $70 \%$ of total Palestinian population [16]. In this research, the collected cross sectional data covers from year 2010 up to year 2015, with 143 observations.

\section{Research Model}

Referring to Figure 1, the framework is adapted to reflect multivariate analysis, where, in this research the examination evaluates significant relationship and effect of size predictor on non-revenue water, staff productivity, collection efficiency, average consumption, average price, operating and maintenance cost, working ratio, and gross profit. This impact may have positive or negative relation. The following diagram sketches this relation.

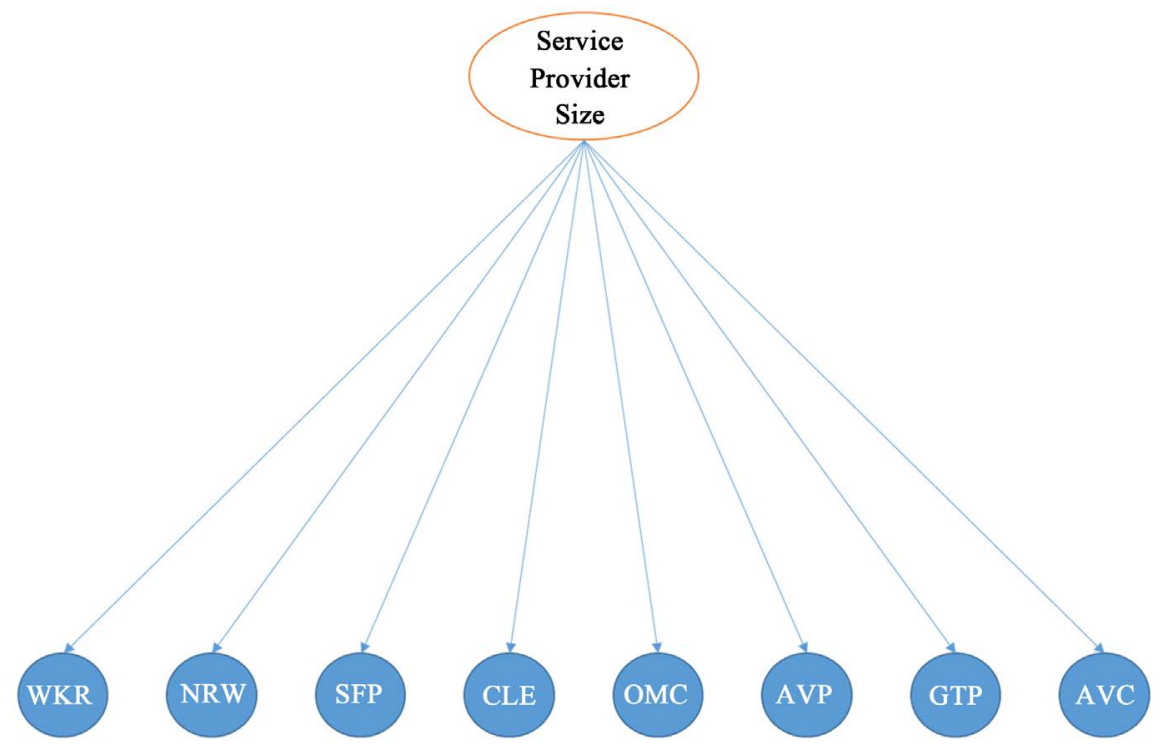

Figure 1. Research model. Where: -; WKR: Working Ratio; NRW: Non-Revenue Water; SFP: Staff Productivity; CEL: Collection Efficiency; OMC: Operating and Maintenance Cost; AVP: Average Price; GTP: Gross Profit; AVC: Average Consumption; SZS: Service Provider Size. 
The size variable is determined according to the Water Sector Regulatory Council based on number of connections of water service providers. However, the response variables are performance indicators collected from water providers and published in annual basis. Since only one predicator and many dependent variables, multivariate analysis of MANOVA is used. The goal of conducting MANOVA thus is to maximally discriminate between distinct groups of people, places, performance areas and things as. [17] [18] and [19].

$$
\begin{aligned}
n_{k m} \sum_{k} \sum_{m}\left(D T_{k m}-G M_{(D T)}\right)^{2} & =n_{k} \sum_{k}\left(D_{k}-G M_{(D)}\right)^{2}+n_{m} \sum_{m}\left(T_{m}-G M_{(T)}\right)^{2} \\
+ & {\left[n_{k m} \sum_{n} \sum_{m}\left(D T_{k m}-G M_{(D T)}\right)^{2}-n_{k} \sum_{k}\left(D_{k}-G M_{(D)}\right)^{2}\right.} \\
- & \left.n_{m} \sum_{m}\left(D_{m}-G M_{(T)}\right)^{2}\right] \\
& S S_{b g}=S S_{D}+S S_{T}+S S_{D T} \\
\sum_{i} \sum_{k} \sum_{m}\left(Y_{i k m}-G M_{(i k m)}\right)^{2}= & n_{k} \sum_{k}\left(D_{k}-G M_{(D)}\right)^{2}+n_{m} \sum_{m}\left(T_{m}-G M_{(T)}\right)^{2} \\
+ & {\left[n_{k m} \sum_{n} \sum_{m}\left(D T_{k m}-G M_{(D T)}\right)^{2}-n_{k} \sum_{k}\left(D_{k}-G M_{(D)}\right)^{2}\right.} \\
- & \left.n_{m} \sum_{m}\left(D_{m}-G M_{(T)}\right)^{2}\right]+\sum_{i} \sum_{k} \sum_{m}\left(Y_{i k m}-D T_{k m}\right)^{2} .
\end{aligned}
$$

\section{Data Analysis and Discussion}

The collected data from Performance Monitoring Reports is analyzed and tested using Statistical Package for Social Science (SPSS). Both descriptive and inferential analyses have been carried out.

Appendix Table 1 summarizes the collected cross sectional data from performance reports of Palestinian water service providers. The table shows 143 observations for near to 65 service providers with coverage period from year 2010 and up to year 2015. However, Appendix Table 3 proposes multiple and significant comparisons between those sizes. The approximate multivariate for Wilk's Lambda analysis as in Appendix Table 2 shows that overall model is significant where $p=0.000$ [20]. Therefore, there is a statistically significant difference in performance of water service providers based on their size, where $F=$ $4.119, p<0.0005$ and Wilk's $\Lambda=0.642$.

$$
\begin{aligned}
& f\left(d f_{1}, d f_{2}\right)=\left(\frac{1-y}{y}\right)\left(\frac{d f_{2}}{d f_{1}}\right) \\
& \text { where } y=\Lambda^{1 / s}, s=\sqrt{\frac{p^{2}\left(d f_{\text {effect }}\right)^{2}-4}{p^{2}+\left(d f_{\text {effect }}\right)^{2}-5}}, \\
& p=\text { number of DVs, } d f_{1}=p\left(d f_{\text {effect }}\right) \\
& d f_{2}=s\left[\left(d f_{\text {error }}\right)-\frac{p-d f_{\text {effect }}+1}{2}\right]-\left[\frac{p\left(d f_{\text {effect }}\right)-2}{2}\right]
\end{aligned}
$$




\subsection{Profitability Analysis}

The first performance area in the descriptive and multiple comparison tables is working ratio; this ratio simply equals the total amount of operating and maintenance expenses incurred by service provider over operating revenue generated during the year. The purpose of this ratio hence is to measure the ability of the service provider to cover operating and maintenance cost from recognized revenue, and whether or not will be remaining amount to cover capital expenditures. The default amount of this ratio may be 1 , wherein total revenue equals total operating expenses. Less than 1 means revenue covers operating expenses with considerable margin. Back to Appendix Table 1, it shows the more the size of service providers the less the working ratio. This can be explained as large scale of service providers can generate more operating profit comparing with small providers $(\mathrm{S}=1.80 \& \mathrm{~L}=1.01)$.

Appendix Table 3 specifies whether or not significant differences among the three sizes of service providers. The table shows there is significant difference between small and medium size from the first side, and also significant difference between small and large size from the other side. However, insignificant difference is found between medium and large size of service providers. The same result is matched with the gross profit ratio, where, Appendix Table 1 shows direct relationship between size of water providers and gross profit. The larger the size of service providers, the more the profit generating accordingly. Appendix Table 3 presents significant difference in gross profit between small and medium, small and large. On the other hand, there is no significant difference appeared between large and medium of service providers in term of gross profit. In aggregates, the two financial indicators work in the same direction and they give the same results. This explains that administrative expenses are not large amount that may affect profitability of service providers, and this confirms that large amount of cost is related to operating and maintenance cost with insignificant in administrative expenses.

This result is matched with other studies, Pervan and Višić [21] investigated the relationship between size of the firm and its profitability. The study proves that firm size has significant positive influence on profitability. A financial data was collected for about ten years to study relationship between size and profit of electrical firms. The results confirm statistically differences between small, medium and large firms size in profit rate. The researchers concluded that small firms have high profit compared with large, and this profit rate increases when those firms grow bigger [22].

As a general rule, the working ratio and gross profit are affected by revenue and cost. The more in billed revenue and less in recognized cost, the more in profit achieved by water service providers. The price of cubic meter sold plays major factor in revenue calculation, therefore, it's necessary to sketch average price and average cost per unit sold, side by side with gross profit and working ratio. Figure 2 demonstrates in clear way the fitted line of average cost and average price per cubic meter sold. The larger the size of service providers, the 


\section{Relationship between Size and Cost, price, Gross and Gross Profit of Palestinian Water Service providers}

20

15

10

5

0

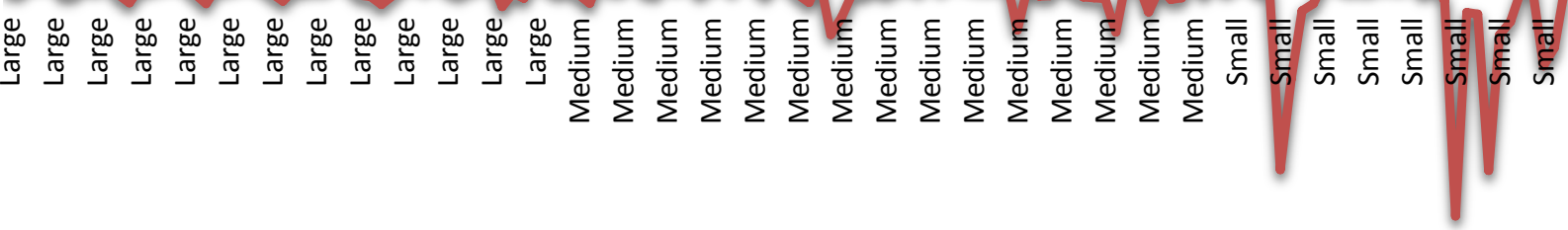

$-10$

Working Ratio $\longrightarrow$ Gross Profit $\quad$ Average Price $\quad$ Operating Cost

Figure 2. Profit \& size.

closer the lines of average price and average cost. The researcher concludes generally that, Palestinian water service providers, especially large providers always set water tariff based on calculated cost.

The diagram comes with the fact that whether small or large service providers, there is also difference in cost and price values within the same size category. Some large service providers incurred high cost and charge high price, and others within same size have less. In Palestine, the water supplies for service providers come from two sources: water production and bulk purchases. It has been noted that water providers incurred less cost once they depend on production rather than purchases. The above chart shows, the more the price, the more the revenue recognized, and therefore, the more in profit margin. To summarize, Figure 2 poses, results when moving from small to large service providers. It is noted that cost and price lines become closer as moving from small to large service providers, more also in gross profit margin, more efficiency in working ratio and difference values in the same size category.

\subsection{Non-Revenue Water Analysis}

Appendix Table 1 shows non-revenue water percent is less in small scale of service providers than in large providers. The non-revenue water is near to $29 \%$ in medium and small, where, its $37 \%$ in large water providers. This result is matched with another study in IBNET over water utilities in 68 countries. Caro- 
line Berg [4] finds a very dense connections and lengthen network especially in urban is likely more maintenance and has more pressure, therefore, more water losses comparing with small and in rural areas. Abdullah Murrar [23] finds negative correlation between the size of service providers in Balkan countries and non-revenue water percentage. The study shows the more the number of population, network connection density, and number of connections, the more the non-revenue water percentage.

In Palestinian water sector, large service providers always have old, dense network compared with small providers. The largest Palestinian water service provider is Jerusalem Water Undertaking, this utility provides water services for near to 62,000 connections, as of more than 370,000 residents. This provider was established in year 1949, so the network was placed in service before 70 years [24]. In the relation of non-revenue water and size of service providers Appendix Table 3 proposes significant difference between small and large service providers. Another statistically significant is also found between medium and large providers. Where, there is no significant difference between medium and small service providers in non-revenue water based on size $(p>0.05=0.887)$.

In this paper, to have real case study in size and performance issues especially in non-revenue, where, there is small Palestinian town supplied water by its small municipality. The number of water connections in this town is 1430 connections. The water network was built before few years to serve total number of population in the town which is near to 7000 residents. This small town performs well in water service provision: wherein, non-revenue water is less than $7 \%$. Collection efficiency is $98 \%$, and working efficiency is 0.99 . In this setting, staff productivity index to 1000 connections is 6 employees. Far from this small town by $15 \mathrm{~km}$, there is large service provider municipality delivers water services to more than 14,300 connections, with total number of population near to 80,000 residents. This large provider suffers from large non-revenue water which is $49 \%$. The collection efficiency is only $51 \%$. Even it has good working efficiency ratio and profitability; it has large number of employees per 1000 connections which are 7.67 employees [16]. The researcher may conclude that size and network place in service date have impact on non-revenue water and other performance areas.

\subsection{Collection Efficiency Analysis}

The ability of service provider to collect water bills from its customers is an indicator for financial sustainability. This research indicates that small Palestinian service providers can collect $64 \%$ from their annual water bills; the medium providers collect $62 \%$, where, large providers collect $63 \%$. From statistical point of view, there are no significant differences between the three sizes based on collection efficiency ( $p=0.669,0.802,0.846)$. A study over water invoices and collections strategies that implemented in Palestinian water service providers shows many predictors lead to increase collection efficiency as strategies of installation prepaid meters, warning on service disconnection, acquire technology, increas- 
ing the number of collection points, quality of water services, quality of other services provided and customers' satisfaction. All those variables motivate the customers to pay their water bills [7]. In Palestinian water sector, some of those strategies are always implemented in small, medium and large sizes of service providers. For instance, many small service providers install prepaid meters instead of postpaid meters. On the other hand, some large service providers follow advance technology and build many collection centers, where in medium size, there are many providers deliver high quality of service with prepaid meter installation. Therefore, it may be difficult to differentiate between small, medium and large scale of service providers in term of collection water bills.

The results of this research which are insignificant differences in collection efficiency based on the sizes of service providers are matched with previous reports. Hope, Foster, Krolikowski, and Cohen [25] examined the impact of mobile water payments in Kenya, Uganda, Tanzania and Zambia for 20 urban water service providers that are serving over 12.5 million customers. Some of those providers are in large scale, where, they serve near to 2.5 million residents with more than 300,000 connections. However, other providers are small, and they serve less than 3000 households. The paper shows that collection efficiency among those service providers is undifferentiated. The small and large have near average value of collection efficiency.

In some countries, the collection efficiency may be compared with other performance indicators to make sure whether or not the problem is in overall performance or just in specific area. A study shows, low level of customers' payment causes increasing non-revenue water level. Since there is little incentive to save water when no intention to pay for it [3]. In this research, negative relationship between non-revenue water percentage and collection efficiency indicators has been found. The more the collection efficiency, the less the non-revenue water. $(\mathrm{r}=-0.152$, correlation is significant at 0.05 level of one-tailed). This implicates that service providers may use the cash collected from customers to invest to decrease the non-revenue water. It also explains that the service provider which makes poor in collection efficiency may have weaknesses in other performance areas, especially in non-revenue water which is core performance indicator.

\subsection{Average Consumption Analysis}

The core function of water providers hence is to deliver water services to the customers. If there is no available water to deliver, then, the customer will not consume required quantity. In Palestine, the customers of Qalqilia and Jericho service providers have average consumption 170 and 271 liters per person per day respectively. Where in Dura and Yata municipalities, the average consumption quantities are 31 liters per person per day. Leaving other things being constant, the main reason for this variation between large and low consumption is water availability. In Qalqilia and Jericho, wherein large consumption quantities, the water providers are delivering in continuous supply mode. However, high intermittent supply is appearing in low consumption areas, i.e. the customers in 
Yatta and Dura may wait more than one month to receive water especially in the summer season.

Appendix Table 1 shows that customers of small and large service providers consume same quantities (Large $=95.4$ and Small $=95$ litters). From statistic point of view, there are no significant differences between small, medium and large service providers based on consumption as indicated in Appendix Table 3 ( $p=0.475,0.966$ and 0.388 ). Explained in other term, the Palestinian water providers are undifferentiated in affording water service to their customers. To see why, remember that Palestinian water service providers can be classified into three broad categories in term of water supplies: firstly, some of them totally depend on their own wells i.e. through water production. Secondly, other providers totally purchase from the bulk provider (West Bank Water Department "WBWD"). The third type is mixing between both purchases and production. Given the fact that most quantities of water supply are purchased, most of Palestinian water providers purchase from the same source. Therefore, no significant difference in the size of service provider is based on customer consumption.

\subsection{Staff Productivity Analysis}

The staff productivity ratio generally indicates the number of employees required to serve 1000 connections. If the number of staff increases relative to the 1000 connections, then, it will be less productivity. Appendix Table 1 shows that small Palestinian water providers require 4.6 employees to serve 1000 connections, where, the large providers require 6 employees to do the same job. However, the medium size can serve the 1000 connections with only $3.8 \mathrm{em}$ ployees. It seems that medium providers are more productive than small and large providers, since they can serve the same number of connections by $82 \%$ and $63 \%$ of small and large providers respectively.

Appendix Table 3 proposes statistic significant relationship between small and large of service providers $(p=0.015)$, and also significant relation between medium and large $(p=0.000)$, where, no significance was found between medium and small providers. The reason for high number of employees in large providers relative to small and medium is poor management in hiring, and some staff may be also recruited to serve water department, but may serve other departments as safeguard staff, drivers and admin officers.

In Palestine, the fact that small size providers have more staff productivity than large size is matched with some previous studies. Marques [26] measured the total factor productivity of the Portuguese water and sewerage services. One aspect of the research was the correlation between the size of service providers and total factor productivity. The researcher found negative relationship between the size of service providers and the productivity. Many indicators have been considered to represent the size of service providers as number of inhabitants, main length, number of customers, and customers' density. All these variables sketch inverse correlation with the productivity of service providers. 


\section{Conclusions \& Policy Implication}

Measuring the effect of size on the performance of Palestinian water service providers is necessary at this phase. The Palestinian water law [27] calls for merging small service providers into large regional utilities. The purpose of this merging is to achieve more efficiency, water availability and more service quality at reasonable price. In Palestinian water sector, a few studies over this subject were prepared. This study evaluates the relationship and effect of size on different performance areas of Palestinian water service providers. Cross sectional data for those service providers have been analyzed using Multivariate Analysis of Variance (MANOVA). This analysis measures the effect and relationship of one predictor i.e. size of Palestinian service providers on eight responsive variables which are non-revenue water, staff productivity, collection efficiency, average consumption, average price, operating and maintenance cost, working ratio and gross profit.

The results show that there are significant differences in different performance areas as working ratio, non-revenue water, staff productivity, average price and gross profit based on service providers' size. In this setting, no significant difference has been found in average daily consumption, operating and maintenance cost per unit, and collection efficiency based on those sizes. The results show that small service providers perform better in non-revenue water, staff productivity and collection efficiency. On the other side, the large service providers are more profitable than small service providers.

In Palestine, the Palestinian Water Authority PWA is the policy maker in water sector. The results of this research may contribute in some performance areas through the reforming process. In non-revenue water side, exploring the specific reasons of low percentage in small providers comparing with large, such as upgrade parts of networks, high metering level and filling water balance, periodically will pave the way to reduce the percentage. Another strategy that small providers always implement, which leads to staff productivity and bills collection efficiency is prepaid meters. This strategy requires less number of staff to visit, read meters, and process invoices to the customers. It leads to high collection efficiency since parts of old and current debts are collected. However, the last result of this research shows that large providers have ability to decrease the cost and increase the average price, therefore, generate more profit comparing with small providers. Adapting those strategies in merging small service providers into large regional utilities may facilitate the merging process and achieve more performance in different areas.

\section{References}

[1] Peda, P., Grossi, G. and Liik, M. (2013) Do Ownership and Size Affect the Performance of Water Utilities? Evidence from Estonian Municipalities. Journal of Management \& Governance, 17, 237-259. https://doi.org/10.1007/s10997-011-9173-6

[2] Makaya, E. and Hensel, O. (2012) Water Distribution Systems Efficiency Assessment Indicators-Concepts and Application. International Journal of Science and Research, 3, Article ID: 02014259. 
[3] McKenzie, R., Siqalaba, Z.N. and Wegelin, W.A. (2012) The State of Non-Revenue Water in South Africa. Water Research Commission Research Report, WRC Report No. TT 522/12.

[4] van den Berg, C. (2014) The Drivers of Non-Revenue Water How Effective Are Non-Revenue Water Reduction Programs? Policy Research Working Paper 6997, Water Global Practice Group, World Bank.

[5] Bonifaz, J. and Itakura, R. (2014) An Analysis of Inefficiency of Big Urban Water Utilities in Latin America. Universidades Del Pacifico, Centro de Investignacion, Documento de Discusión CIUP DD1413.

[6] Connell, W. (2014) Economic Impact of Late Payments. Economic Papers 531, European Commission. September 2014.

[7] Murrar, A. (2017) The Water Invoices and Customers' Payment Motivational Strategies: An Empirical Study on Palestinian Water Service Providers. EPRA International Journal of Economic and Business Review, 5, 5-20.

[8] Mugabi, J., Kayaga, S., Smout, I. and Njiru, C. (2010) Determinants of Customer Decisions to Pay Utility Water Bills Promptly. Water Policy, 12, 220-236.

https://doi.org/10.2166/wp.2009.096

[9] Tynan, N. and Kingdom, B. (2005) Optimal Size for Utilities? Returns of Scale to Water: Evidence from Benchmarking. Note No. 283, The World Bank, Washington DC.

[10] Leung, D., Meh, C. and Terajima, Y. (2008) Firm Size and Productivity. Bank of Canada Working Papers, Document de Travail 2008-45.

[11] Tsagarakis, K.P. (2013) Does Size Matter? Operating Cost Coverage for Water Utilities. Water Resources Management, 27, 1551-1562. https://doi.org/10.1007/s11269-012-0256-1

[12] Garcia, S. and Thomas, A. (2001) The Structure of Municipal Water Supply Costs: Application to a Panel of French Local Communities. Journal of Productivity Analysis, 16, 5-29. https://doi.org/10.1023/A:1011142901799

[13] González-Gómez, F. and García-Rubio, M.Á. (2008) Efficiency in the Management of Urban Water Services. What Have We Learned after Four Decades of Research? Hacienda Pública Españolal Revista de Economía Pública, 185, 39-67.

[14] Andey, S.P. and Kelkar, P.S. (2009) Influence of Intermittent and Continuous Modes of Water Supply on Domestic Water Consumption. Water Resources Management, 23, 2555-2566. https://doi.org/10.1007/s11269-008-9396-8

[15] Water Sector Regulatory Council (2014) Water Services Providers Performance Report 2014. WSRC Hardcopy and Softcopy Publishing Report.

[16] Water Sector Regulatory Council (2015) Water Services Providers Performance Report 2015. WSRC Hardcopy and Softcopy Arabic Version, Publishing Report.

[17] Grice, J. and Iwasaki, M. (2007) A Truly Multivariate Approach to MANOVA. Applied Multivariate Research, 12, 199-226.

[18] Huberty, C.J. and Olejnik, S. (2006) Applied MANOVA and Discriminant Analysis. 2nd Edition, John Wiley \& Sons, Hoboken, NJ. https://doi.org/10.1002/047178947x

[19] Warne, R. (2014) A Primer on Multivariate Analysis of Variance (MANOVA) for Behavioral Scientists. Practical Assessment, Research \& Evaluation, 19.

[20] Haase, R. and Ellis, M. (1987) Multivariate Analysis of Variance. Journal of Counseling Psychology, 34, 404-413. https://doi.org/10.1037/0022-0167.34.4.404

[21] Pervan, M. and Višić, J. (2012) Influence of Firm Size on Its Business Success. Croatian Operational Research Review (CRORR), 3, 213-223. 
[22] Ammar, A., et al. (2003) Indicator Variables Model of Firm's Size-Profitability Relationship of Electrical Contractors Using Financial and Economic Data. Journal of Construction Engineering and Management, 129. https://doi.org/10.1061/(ASCE)0733-9364(2003)129:2(192)

[23] Murrar, A. (2017) The Determinants of Non-Revenue Water in Balkan Countries. American Journal of Water Science and Engineering, 3, 18-27.

[24] Jerusalem Water Undertaking (2016) Foundation of JWU. Historical Background. Published on May 23, 2016. http://www.jwu.org/jwu/?p=1698\&lang=en

[25] Hope, R.A., Foster, T., Krolikowski, A. and Cohen, I. (2011) Mobile Water Payment Innovations in Urban Africa. December 2011, School of Geography and the Environment and Skoll. Centre for Social Entrepreneurship at Saïd Business School, Oxford University, UK.

[26] Marques, R. (2008) Measuring the Total Factor Productivity of the Portuguese Water and Sewerage Services. Economia Aplicada, 12. https://doi.org/10.1590/s1413-80502008000200003

[27] State of Palestine (2014) Decree No. 14 for Year 2014 Relating to the Water Law. Palestinian Water Authority, Articles 45, 46 and 47. 


\section{Appendix}

Table 1. Descriptive statistics.

\begin{tabular}{|c|c|c|c|c|}
\hline & Size & Mean & Std. Deviation & $\mathbf{N}$ \\
\hline \multirow{4}{*}{ Working Ratio } & Small & 1.8048 & 1.75227 & 33 \\
\hline & Medium & 1.0556 & 0.42323 & 59 \\
\hline & Large & 1.0159 & 0.25077 & 51 \\
\hline & Total & 1.2143 & 0.94493 & 143 \\
\hline \multirow{4}{*}{ Non-Revenue Water } & Small & 29.5758 & 13.71366 & 33 \\
\hline & Medium & 29.2395 & 11.05185 & 59 \\
\hline & Large & 37.1988 & 8.28170 & 51 \\
\hline & Total & 32.1557 & 11.42957 & 143 \\
\hline \multirow{4}{*}{ Staff Productivity } & Small & 4.6715 & 3.06750 & 33 \\
\hline & Medium & 3.8641 & 1.84362 & 59 \\
\hline & Large & 6.0247 & 2.61035 & 51 \\
\hline & Total & 4.8210 & 2.61038 & 143 \\
\hline \multirow{4}{*}{ Collection Efficiency } & Small & 64.4242 & 31.39470 & 33 \\
\hline & Medium & 61.9953 & 27.31640 & 59 \\
\hline & Large & 62.9639 & 20.15689 & 51 \\
\hline & Total & 62.9013 & 25.90054 & 143 \\
\hline \multirow{4}{*}{ O \& M Cost } & Small & 4.3733 & 2.88436 & 33 \\
\hline & Medium & 4.0298 & 1.86629 & 59 \\
\hline & Large & 4.2896 & 2.52551 & 51 \\
\hline & Total & 4.2017 & 2.35907 & 143 \\
\hline \multirow{4}{*}{ Average Price } & Small & 3.02606 & 1.712332 & 33 \\
\hline & Medium & 3.77856 & 1.757483 & 59 \\
\hline & Large & 3.97373 & 2.142801 & 51 \\
\hline & Total & 3.67451 & 1.916633 & 143 \\
\hline \multirow{4}{*}{ Gross Profit } & Small & -1.00202 & 2.00117 & 33 \\
\hline & Medium & -0.12720 & 0.44503 & 59 \\
\hline & Large & -0.06890 & 0.25012 & 51 \\
\hline & Total & -0.30829 & 1.0730 & 143 \\
\hline \multirow{4}{*}{ Consumption } & Small & 94.9924 & 49.36105 & 33 \\
\hline & Medium & 87.0861 & 62.07258 & 59 \\
\hline & Large & 95.4808 & 34.37540 & 51 \\
\hline & Total & 91.9045 & 50.55069 & 143 \\
\hline
\end{tabular}

Table 2. Multivariate tests ${ }^{\mathrm{a}}$.

\begin{tabular}{ccccccc}
\hline & Effect & Value & F & Hypothesis df & Error df & Sig. \\
\hline \multirow{4}{*}{ Intercept } & Pillai's Trace & 0.993 & $2263.235^{\mathrm{b}}$ & 8.000 & 133.000 & 0.000 \\
& Wilks' Lambda & 0.007 & $2263.235^{\mathrm{b}}$ & 8.000 & 133.000 & 0.000 \\
& Hotelling's Trace & 136.134 & $2263.235^{\mathrm{b}}$ & 8.000 & 133.000 & 0.000 \\
& Roy's Largest Root & 136.134 & $2263.235^{\mathrm{b}}$ & 8.000 & 133.000 & 0.000 \\
& Pillai's Trace & 0.389 & 4.049 & 16.000 & 268.000 & 0.000 \\
\cline { 2 - 6 } SZE & Wilks' Lambda & 0.642 & $4.119^{\mathrm{b}}$ & 16.000 & 266.000 & 0.000 \\
& Hotelling's Trace & 0.508 & 4.189 & 16.000 & 264.000 & 0.000 \\
& Roy's Largest Root & 0.377 & $6.316^{\mathrm{c}}$ & 8.000 & 134.000 & 0.000 \\
\hline
\end{tabular}


Table 3. Multiple comparison.

\begin{tabular}{|c|c|c|c|c|c|c|c|}
\hline \multirow{2}{*}{$\begin{array}{c}\text { Dependent } \\
\text { Variable }\end{array}$} & \multirow{2}{*}{$\begin{array}{l}\text { (I) } \\
\text { Size }\end{array}$} & \multirow{2}{*}{$\begin{array}{l}(J) \\
\text { Size }\end{array}$} & \multirow{2}{*}{$\begin{array}{c}\text { Mean } \\
\text { Difference (I-J) }\end{array}$} & \multirow{2}{*}{ Std. Error } & \multirow{2}{*}{ Sig. } & \multicolumn{2}{|c|}{ 95\% Confidence Interval } \\
\hline & & & & & & Lower Bound & Upper Bound \\
\hline \multirow{6}{*}{$\begin{array}{l}\text { Working } \\
\text { Ratio }\end{array}$} & \multirow{2}{*}{$S$} & M & $0.7493^{*}$ & 0.19424 & 0.000 & 0.3652 & 1.1333 \\
\hline & & $\mathrm{L}$ & $0.7890^{*}$ & 0.19963 & 0.000 & 0.3943 & 1.1836 \\
\hline & \multirow{2}{*}{ M } & S & $-0.7493^{\star}$ & 0.19424 & 0.000 & -1.1333 & -0.3652 \\
\hline & & $\mathrm{L}$ & 0.0397 & 0.17085 & 0.817 & -0.2981 & 0.3775 \\
\hline & \multirow{2}{*}{$\mathrm{L}$} & S & $-0.7890^{*}$ & 0.19963 & 0.000 & -1.1836 & -0.3943 \\
\hline & & M & -0.0397 & 0.17085 & 0.817 & -0.3775 & 0.2981 \\
\hline \multirow{6}{*}{$\begin{array}{c}\text { Non-Revenue } \\
\text { Water }\end{array}$} & \multirow{2}{*}{ S } & M & 0.3363 & 2.36214 & 0.887 & -4.3338 & 5.0063 \\
\hline & & $\mathrm{L}$ & $-7.6231^{*}$ & 2.42768 & 0.002 & -12.4227 & -2.8234 \\
\hline & \multirow{2}{*}{ M } & S & -0.3363 & 2.36214 & 0.887 & -5.0063 & 4.3338 \\
\hline & & $\mathrm{L}$ & $-7.9593^{*}$ & 2.07769 & 0.000 & -12.0670 & -3.8516 \\
\hline & \multirow{2}{*}{$\mathrm{L}$} & S & $7.6231^{*}$ & 2.42768 & 0.002 & 2.8234 & 12.4227 \\
\hline & & M & $7.9593^{*}$ & 2.07769 & 0.000 & 3.8516 & 12.0670 \\
\hline \multirow{6}{*}{$\begin{array}{c}\text { Staff } \\
\text { Productivity }\end{array}$} & \multirow{2}{*}{$S$} & M & 0.8074 & 0.53212 & 0.131 & -0.2446 & 1.8595 \\
\hline & & $\mathrm{L}$ & $-1.3532^{\star}$ & 0.54689 & 0.015 & -2.4344 & -0.2720 \\
\hline & \multirow{2}{*}{ M } & S & -0.8074 & 0.53212 & 0.131 & -1.8595 & 0.2446 \\
\hline & & $\mathrm{L}$ & $-2.1606^{\star}$ & 0.46804 & 0.000 & -3.0860 & -1.2353 \\
\hline & \multirow{2}{*}{$\mathrm{L}$} & S & $1.3532^{*}$ & 0.54689 & 0.015 & 0.2720 & 2.4344 \\
\hline & & M & $2.1606^{\star}$ & 0.46804 & 0.000 & 1.2353 & 3.0860 \\
\hline \multirow{6}{*}{$\begin{array}{l}\text { Collection } \\
\text { Efficiency }\end{array}$} & S & M & 2.4290 & 5.66649 & 0.669 & -8.7740 & 13.6320 \\
\hline & 3 & $\mathrm{~L}$ & 1.4603 & 5.82373 & 0.802 & -10.0535 & 12.9741 \\
\hline & $M$ & S & -2.4290 & 5.66649 & 0.669 & -13.6320 & 8.7740 \\
\hline & $M$ & $\mathrm{~L}$ & -0.9687 & 4.98412 & 0.846 & -10.8225 & 8.8852 \\
\hline & $\mathrm{I}$ & $S$ & -1.4603 & 5.82373 & 0.802 & -12.9741 & 10.0535 \\
\hline & $\mathbf{L}$ & M & 0.9687 & 4.98412 & 0.846 & -8.8852 & 10.8225 \\
\hline & $\mathrm{S}$ & M & 0.3435 & 0.51544 & 0.506 & -0.6755 & 1.3626 \\
\hline & 3 & $\mathrm{~L}$ & 0.0837 & 0.52974 & 0.875 & -0.9636 & 1.1311 \\
\hline O \& M Most & $M$ & S & -0.3435 & 0.51544 & 0.506 & -1.3626 & 0.6755 \\
\hline a dit cost & $M$ & $\mathrm{~L}$ & -0.2598 & 0.45337 & 0.568 & -1.1561 & 0.6366 \\
\hline & $\mathrm{I}$ & S & -0.0837 & 0.52974 & 0.875 & -1.1311 & 0.9636 \\
\hline & $\mathrm{L}$ & M & 0.2598 & 0.45337 & 0.568 & -0.6366 & 1.1561 \\
\hline & $\mathrm{S}$ & M & -0.75250 & 0.411849 & 0.070 & -1.56675 & 0.06175 \\
\hline & 0 & $\mathrm{~L}$ & $-0.94766^{\star}$ & 0.423277 & 0.027 & -1.78451 & -0.11082 \\
\hline Average & $M$ & $S$ & 0.75250 & 0.411849 & 0.070 & -0.06175 & 1.56675 \\
\hline Price & $M$ & $\mathrm{~L}$ & -0.19517 & 0.362253 & 0.591 & -0.91136 & 0.52103 \\
\hline & $\mathrm{I}$ & S & $0.94766^{*}$ & 0.423277 & 0.027 & 0.11082 & 1.78451 \\
\hline & $\mathrm{L}$ & M & 0.19517 & 0.362253 & 0.591 & -0.52103 & 0.91136 \\
\hline & 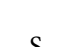 & M & $-0.87481^{\star}$ & 0.21951 & 0.000 & -1.3088 & -0.44082 \\
\hline & 3 & $\mathrm{~L}$ & $-0.93312^{\star}$ & 0.22560 & 0.000 & -1.37915 & -0.48709 \\
\hline Gross & $M$ & $S$ & $0.87481^{*}$ & 0.21951 & 0.000 & 0.44082 & 1.3088 \\
\hline Profit & $\mathrm{N}$ & $\mathrm{L}$ & -0.05830 & 0.19307 & 0.763 & -0.44003 & 0.32341 \\
\hline & $\mathrm{I}$ & $S$ & $0.93312^{*}$ & 0.22560 & 0.000 & 0.487091 & 1.3791 \\
\hline & $\mathrm{L}$ & M & 0.058306 & 0.193078 & 0.763 & -0.323419 & 0.44003 \\
\hline & $S$ & M & 7.9063 & 11.03101 & 0.475 & -13.9026 & 29.7152 \\
\hline & $\mathrm{S}$ & $\mathrm{L}$ & -0.4884 & 11.33710 & 0.966 & -22.9024 & 21.9257 \\
\hline Consumntion & $M$ & S & -7.9063 & 11.03101 & 0.475 & -29.7152 & 13.9026 \\
\hline Consumption & $\mathrm{N} 1$ & $\mathrm{~L}$ & -8.3947 & 9.70263 & 0.388 & -27.5773 & 10.7879 \\
\hline & $\mathrm{I}$ & S & 0.4884 & 11.33710 & 0.966 & -21.9257 & 22.9024 \\
\hline & $\mathrm{L}$ & M & 8.3947 & 9.70263 & 0.388 & -10.7879 & 27.5773 \\
\hline
\end{tabular}


Submit or recommend next manuscript to SCIRP and we will provide best service for you:

Accepting pre-submission inquiries through Email, Facebook, LinkedIn, Twitter, etc. A wide selection of journals (inclusive of 9 subjects, more than 200 journals)

Providing 24-hour high-quality service

User-friendly online submission system

Fair and swift peer-review system

Efficient typesetting and proofreading procedure

Display of the result of downloads and visits, as well as the number of cited articles Maximum dissemination of your research work

Submit your manuscript at: http://papersubmission.scirp.org/

Or contact jwarp@scirp.org 